\title{
Communication between general practitioners and medical specialists in the referral process: a cross-sectional survey in 34 countries
}

Giacomo Scaioli ${ }^{1}$, Willemijn L. A. Schäfer ${ }^{2}$, Wienke G. W. Boerma ${ }^{3}$, Peter M. M. Spreeuwenberg ${ }^{3}$, François G. Schellevis ${ }^{3,4}$ and Peter P. Groenewegen ${ }^{3,5^{*}}$

\begin{abstract}
Background: The communication of relevant patient information between general practitioners (GPs) and medical specialists is important in order to avoid fragmentation of care thus achieving a higher quality of care and ensuring physicians' and patients' satisfaction. However, this communication is often not carried out properly. The objective of this study is to assess whether communication between GPs and medical specialists in the referral process is associated with the organisation of primary care within a country, the characteristics of the GPs, and the characteristics of the primary care practices themselves.
\end{abstract}

Methods: An analysis of a cross-sectional survey among GPs in 34 countries was conducted. The odds ratios of the features that were expected to relate to higher rates of referral letters sent and communications fed back to GPs were calculated using ordered logistic multilevel models.

Results: A total of 7183 GPs from 34 countries were surveyed. Variations between countries in referral letters sent and feedback communication received did occur. Little of the variance between countries could be explained. GPs stated that they send more referral letters, and receive more feedback communications from medical specialists, in countries where they act as gatekeepers, and when, in general, they interact more with specialists. GPs reported higher use of referral letters when they had a secretary and/or a nurse in their practice, used health information technologies, and had greater job satisfaction.

Conclusions: There are large differences in communication between GPs and medical specialists. These differences can partly be explained by characteristics of the country, the GP and the primary care practice. Further studies should also take the organisation of secondary care into account.

Keywords: Continuity of care, Communication, Primary care, Secondary care, Referrals

\footnotetext{
* Correspondence: p.groenewegen@nivel.nl

${ }^{3}$ NIVEL (Netherlands Institute for Health Services Research), PO box 1568, Utrecht 3500BN, The Netherlands

${ }^{5}$ Department of Sociology and Department of Human Geography, Utrecht University, P.O. Box 80.115, Utrecht 3508 TC, The Netherlands

Full list of author information is available at the end of the article
}

(c) The Author(s). 2020 Open Access This article is licensed under a Creative Commons Attribution 4.0 International License, which permits use, sharing, adaptation, distribution and reproduction in any medium or format, as long as you give appropriate credit to the original author(s) and the source, provide a link to the Creative Commons licence, and indicate if changes were made. The images or other third party material in this article are included in the article's Creative Commons licence, unless indicated otherwise in a credit line to the material. If material is not included in the article's Creative Commons licence and your intended use is not permitted by statutory regulation or exceeds the permitted use, you will need to obtain permission directly from the copyright holder. To view a copy of this licence, visit http://creativecommons.org/licenses/by/4.0/ The Creative Commons Public Domain Dedication waiver (http://creativecommons.org/publicdomain/zero/1.0/) applies to the data made available in this article, unless otherwise stated in a credit line to the data. 


\section{Background}

Continuity of care is one of the key elements of modern healthcare systems [1-4]. An increasing number of patients with chronic diseases and multimorbidity [5] usually receive health care from both general practitioners (GPs) and several medical specialists. This highlights the need for a connection between all the health care events of each patient, in short that care is coordinated [4, 6]. Continuity of care contains three major dimensions. Firstly, there must be personal continuity, meaning that patients have a personal physician who knows and follows them in separate care settings. Second is team continuity, which entails that relevant patient information is communicated between physicians within a care setting. Finally, cross-boundary continuity is important, that is the communication of relevant patient information and cooperation between physicians from different settings [2, 3, 7-9]. Previous studies showed that high rates of communication between physicians were associated with better patient outcomes and greater satisfaction among both patients and physicians [10-13]. Low rates of communication seem to decrease the quality of care due to delayed diagnoses and treatments, repeated diagnostic examinations, increased rates of adverse events, and avoidable hospitalisations [10, 14-17].

Communication between physicians usually takes place when a patient is referred by one physician to another. As such, it represents one of the most important steps in the referral process itself [18]. As referrals usually occur from a GP to a medical specialist, [19] it is relevant to focus our attention especially on these professionals. Despite this relevance, the exchange of patient information between GPs and medical specialists through referral letters by GPs and feedback reports by medical specialists has been demonstrated to be performed inadequately [20]. Studies conducted in the USA showed that in only $50 \%$ of the cases medical specialists did receive information about patients referred by general paediatricians $[11,21]$. Another study stated that $68 \%$ of the medical specialists do not receive information from GPs [14].

Research has shown that communication between primary and secondary care was better when GPs indicated that they had 'adequate time' during consultations with patients [14, 22]. In addition, the presence of a nurse in the practice and the use of health information technologies (HITs), and/or a greater integration between GPs and medical specialists, have shown to improve communication [21-24]. Nurses and HITs can help GPs in the production and the delivery of referral letters, and also in obtaining feedback from the specialists by chasing them up.

So far, studies on correlates of communication between primary and secondary care were performed in single countries. International studies on referrals, meanwhile, have not focused on this specific topic [25]. The organisation of primary care varies greatly between countries which might affect attitudes and practices of GPs and, therefore, rates of communication between GPs and medical specialists [26, 27]. By using data from 34 countries, our study investigates whether differences between countries in the organisation of their primary care systems are related to the rate of communication between primary and secondary care. We then assess whether characteristics of GPs and primary care practices are associated with this communication, independent of the organisation of the primary care system in which GPs operate.

The aim of our study is to assess what are the factors which explain the variation between countries in the rates of communication between GPs and medical specialists in referrals. Can they be explained by differences in how primary care is organised at the national level and by differences in the characteristics of GPS and primary care practices (Fig. 1)? We hypothesise that, in the referral process from a GP to a medical specialist:

1. Health care systems that are more orientated towards primary care, $[26,27]$ achieve higher rates of communication in both directions (referral letters sent and feedback communication received);

2. GPs who report a higher workload and lower satisfaction send fewer referral letters to medical specialists than those who reported a lower workload and greater job satisfaction;

3. GPs working with support staff and computer facilities, achieve higher rates of communication to, and from, medical specialists;

4. GPs who have more informal interactions with specialists have more communication to, and from, medical specialists.

\section{Methods}

To assess the rates of communication between GPs and medical specialists in 34 countries we used data from the QUALICOPC study (Quality and Costs of Primary Care in Europe). In this study, GPs in 31 European countries were included (Austria, Belgium, Bulgaria, Cyprus, Czech Republic, Denmark, England, Estonia, Finland, Germany, Greece, Hungary, Iceland, Ireland, Italy, Latvia, Lithuania, Luxembourg, Malta, the Netherlands, Norway, Poland, Portugal, Romania, Slovakia, Slovenia, Spain, Sweden, Switzerland, the Former Yugoslav Republic of (FYR) Macedonia, Turkey) and three non-European countries (Australia, Canada, New Zealand). We aimed to achieve a nationally representative sample of GPs completing a questionnaire in each country (target size: $N=220$; Cyprus, Iceland, Luxembourg, and Malta $N=80$ ). Only 


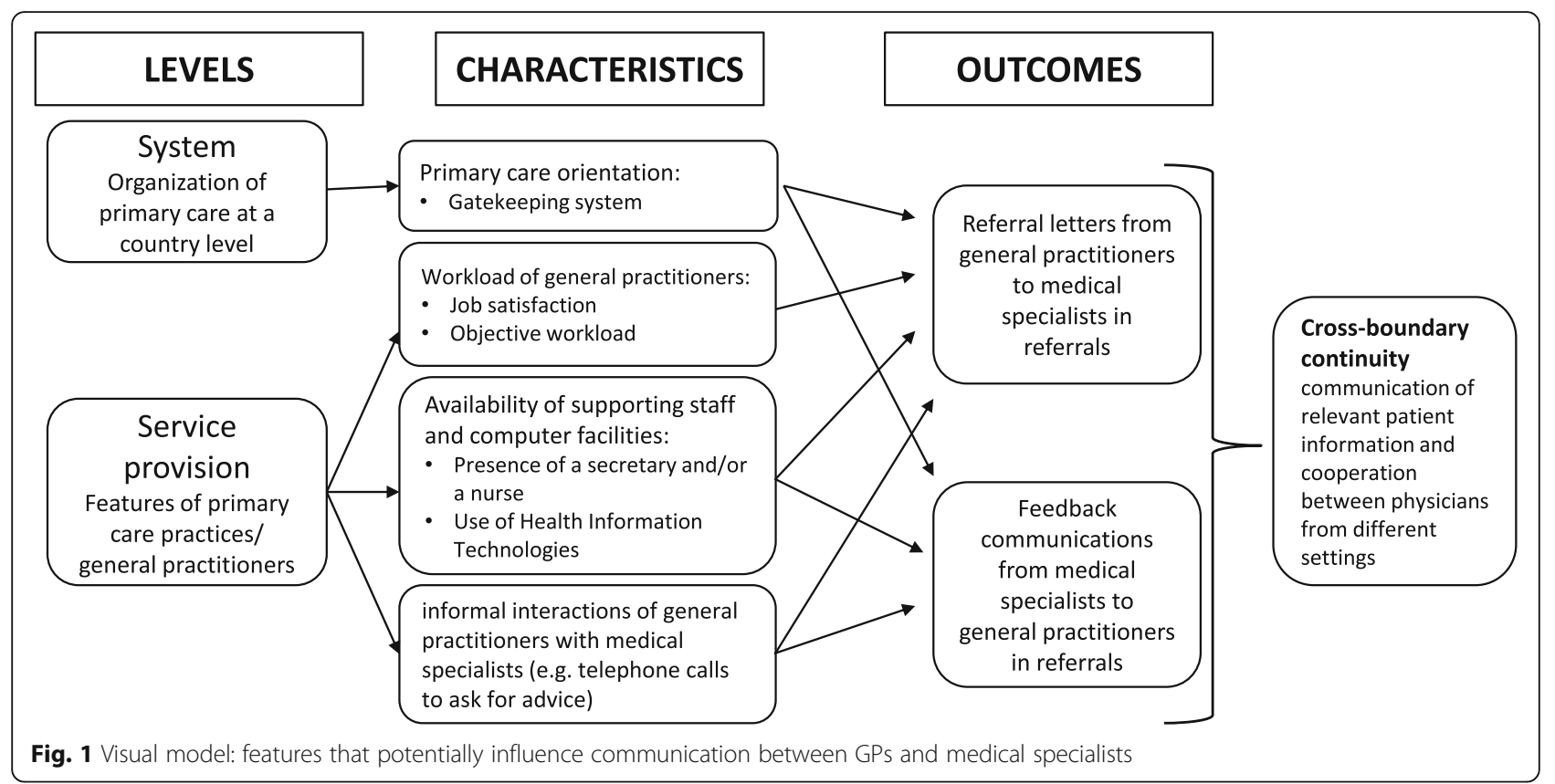

one GP per practice or health centre participated in the study. Questionnaires were completed anonymously either on paper or electronically. Data collection took place between October 2011 and December 2013. Details about the study protocol, including the required sample sizes, the development of the questionnaire, and the participation of GPs have been published elsewhere [28-30].

\section{Measures}

\section{Communication}

The indicators of communication between GPs and medical specialists were derived from the following questions:

- To what extent do you use referral letters (including details on provisional diagnosis and possible test results) when you refer patients to a medical specialist?

- To what extent do medical specialists inform you after they have finished the treatment or diagnostics of your patients?

Possible answers for the first question were "for all patients whom I refer", "for most patients", "for a minority of patients" and "seldom or never". Possible answers for the second question were "(Almost) always", "Usually", "Occasionally", and "Seldom or Never".

\section{Organisation of primary care}

Whether or not a country is oriented towards primary care $[26,27]$ was established on the basis of the presence of a gatekeeping system. We derived these data in 30 countries from the Primary Health Care Activity Monitor (PHAMEU) study [31, 32]. Data from four countries (Australia, Canada, New Zealand and FYR Macedonia) were collected using the same methods as the PHAMEU study [33]. We considered countries with a gatekeeping system as being those with a full or partial (for a selection of referral physicians) gatekeeping system. We considered countries with no gatekeeping system as those with no mandatory gatekeeping, regardless of the presence of incentives for patients who contact the GP as a first step [32].

\section{Workload and job satisfaction}

Workload was defined objectively as the amount of time that certain activities consume or the frequency with which certain activities take place'. [34] We used variables from the questionnaire that assessed the number of patient visits and telephone calls in a normal working day, and the number of weekly working hours. For job satisfaction, [34] we used a score based on six statements in the questionnaire. GPs were asked to agree, or disagree, with the following statements: 'I feel that some parts of my work do not really make sense', 'My work still interests me as much as it ever did', 'My work is overloaded with unnecessary administrative detail', 'I have too much stress in my current job', 'Being a GP is a wellrespected job' and 'in my work there is a good balance between effort and reward'. A higher score indicates greater job satisfaction. The internal consistency (Cronbach's alpha), computed over the whole dataset, is 0.68 . 


\section{Support staff and computer facilities}

We included data about the availability of a secretary and/or a nurse [35] in the primary care practice (Yes/ No). 'Use of HIT in the referral process' was derived from a question asking whether GPs use the computer to send referral letters to specialists (Yes/No).

\section{Informal interactions}

We calculated a score, based on the answers to the question 'How often do you ask advice from the following medical specialists?', the different medical specialists being: paediatrician, internist, gynaecologist, neurologist, dermatologist, geriatrician, psychiatrist, radiologist. A higher score indicates higher frequency of interactions.

\section{Statistical analysis}

Firstly, we calculated the distribution of answers to the two communication questions. Next, we applied ordered logistic multilevel models to analyse the relationship between the two outcome variables and independent variables. Cases with missing data were excluded list-wise. Continuous variables were centred around the mean. We included two levels (country and GP) in our models. For each outcome variable, an initial model with background variables (age and gender of GPs, practice location and employment status of GPs) was estimated. Then, for the outcome 'rate of referral letters', we performed four cumulative models. We added variables as follows: 1) The objective workload and job satisfaction of GPs; 2) The availability of support staff and computer facilities; 3) The informal interactions of GPs with medical specialists; and 4) The organisation of primary care at a country level (gatekeeping system in place). For the outcome 'reception of feedback communications from specialists' we estimated just three models, since we did not hypothesise that the objective workload and job satisfaction of GPs might be associated with this outcome. We only present the final models in the tables. For each of the two outcome variables we calculated the intraclass correlation (ICC). We used $\pi^{2} / 3$ as approximation of the individual level variance [36]. We also calculated the percentage of reduction of variance in the final model at the country level. The total variance was approximated by using the linear predictor approach as described by Snijders and Bosker [36]. The level of statistical significance was set at $p<0.05$. Descriptive and multilevel analysis were performed using Stata version 13.0.

\section{Results}

\section{Rates of communication}

A total of 7183 GPs completed the questionnaire (QUALICOPC database version 4.2). The median participation rate was 30\% [30]. The background characteristics of GPs are described in Table 1.
Table 1 Characteristics of GPs, primary care practices, and countries included in the study $(N=7183)$

\begin{tabular}{|c|c|c|c|}
\hline $\begin{array}{l}\text { Characteristics of } \\
\text { primary care practices } \\
\text { and GPs }\end{array}$ & & $\begin{array}{l}\text { Median and } \\
\text { interquartile } \\
\text { range }\end{array}$ & $\begin{array}{l}\text { Number of } \\
\text { missing } \\
\text { observations }\end{array}$ \\
\hline Gender (percentage of females) & 52.5 & & 28 \\
\hline Age $\left(\right.$ mean $\left.\pm S D^{a}\right)$ & $50.3 \pm 9.7$ & $52(43-58)$ & 74 \\
\hline Practice location (percentages) & & & 150 \\
\hline Big (inner)city & 31.4 & & \\
\hline Suburbs or small town & 35.1 & & \\
\hline Urban-rural or rural & 33.5 & & \\
\hline $\begin{array}{l}\text { Employment status } \\
\text { (percentages) }\end{array}$ & & & 246 \\
\hline Salaried & 35.0 & & \\
\hline Self-employed & 64.0 & & \\
\hline Mixed & 1 & & \\
\hline $\begin{array}{l}\text { Number of face-to face } \\
\text { visits in a normal working } \\
\text { day (mean } \pm S D^{a} \text { ) }\end{array}$ & $31.0 \pm 16.0$ & $28(20-40)$ & 49 \\
\hline $\begin{array}{l}\text { Number of telephone calls } \\
\text { in a normal working day } \\
\left(\text { mean } \pm \mathrm{SD}^{\mathrm{a}}\right)\end{array}$ & $8.2 \pm 7.6$ & $5(3-10)$ & 49 \\
\hline $\begin{array}{l}\text { Job satisfaction } \\
\left(\text { mean } \pm \mathrm{SD}^{\mathrm{a}}\right)\end{array}$ & $2.5 \pm 0.3$ & $2,5(2.2-2.8)$ & 52 \\
\hline $\begin{array}{l}\text { Availability of supporting } \\
\text { staff (percentages): }\end{array}$ & & & 137 \\
\hline $\begin{array}{l}\text { Absence of secretary } \\
\text { and nurse }\end{array}$ & 7.4 & & \\
\hline $\begin{array}{l}\text { presence of a secretary } \\
\text { or a nurse }\end{array}$ & 43.1 & & \\
\hline $\begin{array}{l}\text { presence of both a } \\
\text { secretary and a nurse }\end{array}$ & 49.5 & & \\
\hline $\begin{array}{l}\text { Use of pc to send referral } \\
\text { letters (percentage of 'yes') }\end{array}$ & 71.0 & & 292 \\
\hline $\begin{array}{l}\text { Interactions between GPs } \\
\text { and specialists (mean } \pm \mathrm{SD}^{\mathrm{a}} \text { ) }\end{array}$ & $1.7 \pm 0.5$ & $1.67(1.2-2.0)$ & 172 \\
\hline \multicolumn{4}{|l|}{ Country characteristics } \\
\hline $\begin{array}{l}\text { Gatekeeping system } \\
\text { in place (percentage } \\
\text { of 'yes') }\end{array}$ & 55.9 & & 0 \\
\hline
\end{tabular}

${ }^{\mathrm{a}} \mathrm{SD}$ Standard Deviation

Figure 2 shows the distributions of answers for the two communication variables by country. The majority $(65.8 \%)$ indicated that they always send letters to a specialist when they refer a patient. There were, however, large differences between countries (e.g., 97.7\% of GPs in Canada and only $6.9 \%$ in Germany). A total of $7.5 \%$ of GPs stated that they sent referral letters for a minority of the patients whom they refer. Furthermore, $6.5 \%$ stated that they 'seldom or never' send referral letters. In some countries (Denmark, Ireland, Malta, the Netherlands, Norway, Slovenia, Spain, England, Australia, Canada, New Zealand) almost all GPs send referral letters for all or most 


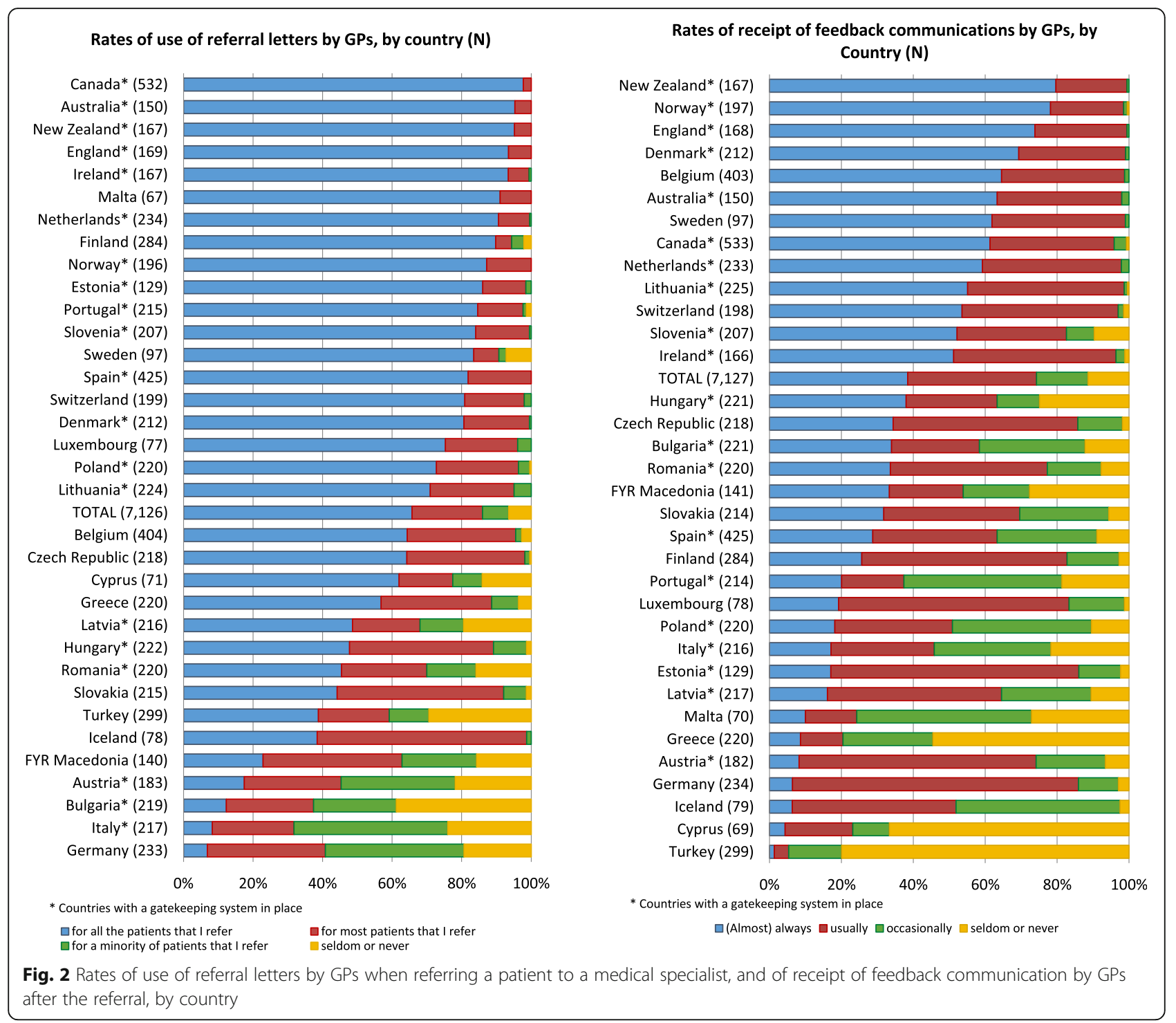

patients In other countries (Austria, Bulgaria, Germany, Italy), however, more than half of the GPs send referral letters seldom or never, or for a minority of patients whom they refer.

In total $38.4 \%$ of GPs '(almost) always' receive feedback communications from specialists, with percentages that range from $79.6 \%$ in New Zealand to $1.3 \%$ in Turkey. Conversely, $11 \%$ of the GPs never receive feedback communications from specialists, with peaks in Turkey (79.9\%) and in Cyprus (66.7\%), and low percentages of GPs who never receive feedback in Belgium, Denmark, Lithuania, the Netherlands, Norway, Sweden, England, Australia, Canada, and New Zealand.

\section{Associated factors}

Tables 2 and 3 show the results of the logistic multilevel models. In countries with a gatekeeping system, GPs reported higher rates of referral letters were sent. The reported use of referral letters was higher among GPs with a higher number of consultations per day and among GPs with a greater job satisfaction. The same holds for the presence of support staff and the use of computers. Moreover, GPs reported higher rates of referral letters were sent, when they have more informal interactions with specialists. The variance at country level is high (Intraclass correlation (ICC): $42 \%$ in the initial model). The proportion of the country level variance explained by this model is 7\%.(Table 2) Comparing the third model (with all GP/ practice characteristics) to the initial model, shows that the country level variance does not decrease with adding $\mathrm{GP} /$ practice characteristics. Hence, there are no marked composition effects. (not in table).

GPs report higher rates of feedback communications when they have higher rates of informal interactions 
Table 2 Ordered logistic multilevel model of rates of referral letters sent by GPs in 34 countries

\begin{tabular}{|c|c|c|c|}
\hline $\begin{array}{l}N_{i}=34 \\
N_{j}=6580\end{array}$ & \multicolumn{2}{|c|}{ Odds Ratio ${ }^{\text {a }}(\mathrm{Cl})$} & $\mathrm{p}$ \\
\hline \multicolumn{4}{|l|}{ GP level } \\
\hline Number of face-to face visits in a normal working day & 1.006 & $(1.001,1.011)$ & 0.009 \\
\hline Number of telephone calls in a normal working days & 0.998 & $(0.990,1.006)$ & 0.499 \\
\hline Number of working hours per week & 1.003 & $(0.997,1.010)$ & 0.297 \\
\hline Job satisfaction & 1.22 & $(1.08,1.39)$ & 0.002 \\
\hline \multicolumn{4}{|l|}{$\begin{array}{l}\text { Availability of support staff } \\
\text { (ref. = no secretary and no nurse) }\end{array}$} \\
\hline presence of a secretary or a nurse & 1.33 & $(1.05,1.70)$ & 0.019 \\
\hline presence of both a secretary and a nurse & 1.37 & $(1.05,1.79)$ & 0.020 \\
\hline Use of pc to send referral letters & 1.78 & $(1.53,2.09)$ & $<0.001$ \\
\hline Interactions between GPs and specialists & 1.45 & $(1.28,1.63)$ & $<0.001$ \\
\hline \multicolumn{4}{|l|}{ Country level } \\
\hline Gatekeeping system in place & 2.80 & $(1.01,7.75)$ & 0.048 \\
\hline Variance Country level (SE) & 2.22 & $(0.56)$ & \\
\hline $\begin{array}{l}\text { Percentage of reduction of variance } \\
{\text { (Country level })^{\mathrm{b}}}\end{array}$ & $7 \%$ & & \\
\hline Intraclass correlation $(\mathrm{ICC})^{c}$ & $40 \%$ & & \\
\hline \multicolumn{4}{|c|}{$\begin{array}{l}\text { a adjusted also for age and gender of GPs, practice location, and employment status of GPs } \\
\text { b this percentage was calculated by using the variance at country level of the initial model (variance initial model }=2.41, \mathrm{SE}=0.60) \\
\text { the ICC of the initial model is } 42 \% \\
\mathrm{~N}_{\mathrm{i}}=\text { number of countries } \\
\mathrm{N}_{\mathrm{j}}=\text { number of GPs } \\
\mathrm{SE}=\text { standard error } \\
\mathrm{Cl}=95 \% \text { confidence interval }\end{array}$} \\
\hline
\end{tabular}

Table 3 Ordered logistic multilevel model of rates of feedback communications received by GPs in 34 countries

\begin{tabular}{|c|c|c|c|}
\hline $\begin{array}{l}N_{i}=34 \\
N_{j}=6637 a\end{array}$ & \multicolumn{2}{|c|}{ Odds ratio $(\mathrm{Cl})$} & $P$ \\
\hline \multicolumn{4}{|l|}{ GP level } \\
\hline \multicolumn{4}{|l|}{$\begin{array}{l}\text { Availability of support staff } \\
\text { (ref. = no secretary and no nurse) }\end{array}$} \\
\hline presence of a secretary or a nurse & 0.90 & $(0.71,1.14)$ & 0.375 \\
\hline presence of both a secretary and a nurse & 0.94 & $(0.73,1.21)$ & 0.630 \\
\hline Use of pc to send referral letters & 0.98 & $(0.85,1.13)$ & 0.786 \\
\hline Interactions between GPs and specialists & 1.18 & $(1.06,1.30)$ & 0.002 \\
\hline \multicolumn{4}{|l|}{ Country level } \\
\hline Gatekeeping system in place & 3.60 & $(1.42,9.13)$ & 0.007 \\
\hline Variance Country level final model (SE) & 1.86 & $(0.46)$ & \\
\hline $\begin{array}{l}\text { Percentage of reduction of variance } \\
\text { (Country level) }^{\mathrm{b}}\end{array}$ & $14 \%$ & & \\
\hline Intraclass correlation (ICC) ${ }^{c}$ & $36 \%$ & & \\
\hline
\end{tabular}

a adjusted also for age and gender of GPs, practice location, and employment status of GPs

${ }^{\mathrm{b}}$ this percentage was calculated by using the variance at a country level of the initial model (variance initial model $=2.17, \mathrm{SE}=0.56$

${ }^{c}$ the ICC of the initial model is $39 \%$

$\mathrm{N}_{\mathrm{i}}=$ number of countries

$\mathrm{N}_{\mathrm{j}}=$ number of GPS

$\mathrm{SE}=$ standard error

$\mathrm{Cl}=95 \%$ confidence interval with specialists. In countries with a gatekeeping system, GPs also report higher rates of feedback communication.(Table 3) Furthermore, for this outcome, variance between countries is high (ICC: $39 \%$ in the initial model). The proportion of country level variance explained by this model is $14 \%$. Comparing the second model (with all GP/practice characteristics) to the initial model, shows that the country level variance does not decrease with adding GP/practice characteristics. Again, there are no marked composition effects. (not in table).

\section{Discussion}

This study aimed to assess whether higher rates of communication between GPs and medical specialists during referrals are associated with the organisation of primary care at the country level and with characteristics of the primary care practices and GPs. Countries in which GPs play a gatekeeper role show higher rates of communication between GPs and medical specialists. A greater job satisfaction of GPs is positively related to the frequency of referral letters sent by GPs. A higher objective workload is associated with more referral letters being sent. The presence of support staff in the practice and the use of computers are positively related to the frequency of referral letters but not with the frequency of feedback communications. More informal interactions between 
GPs and specialists, for example through the use of telephone calls to ask for advice, is associated with higher frequencies of both referral letters and feedback communications.

Previously, a lower subjective workload (and therefore greater job satisfaction) was found to be associated with better performance by GPs and with greater patients' satisfaction with their GPs [37]. The number of consultations could, possibly, not be a valid indicator of workload, because the time these consultations take might also be important. Moreover, GPs' workloads are also determined by other tasks [38]. Our results are only partially consistent with a previous study conducted in the USA, in which the involvement of a nurse at the primary care practice was associated with higher rates of feedback communication received by GPs. But also the use of HITs was associated with higher reports of sending and receiving communications only by medical specialists alone, and not by GPs [22].

Our results confirm the need for GPs to play a pivotal role within health care organisations. Apparently, this is also recognised by specialists, who are more prone to sending feedback communications to GPs if they know that GPs have a central role in the management of care of their patients. This will be the case in countries with a gatekeeping system in place.

The results of this study can be useful for decision makers. Apparently, simple, modifiable features of GPs' everyday practice, such as the use of a computer, the support of a secretary and/or a nurse, and a high number of interactions with specialists, may be helpful for the delivery of services of a better quality. In countries such as Belgium, Greece, and Italy, at least one quarter of the practices do not have a secretary or a nurse. In these countries, policies aimed at favouring the employment of such professionals might be promoted [39]. At the national and regional level decision makers can implement electronic patients' health record systems [40]. These systems have shown to be useful in improving the share of patients' information among physicians [23]. Decision makers may also play a role in promoting interactions between health care providers. Policies aimed at building a network that allows regular contacts between GPs and medical specialists seem to be useful in improving communication in both directions when a patient is referred. Interaction between different health care professionals has been associated with better health outcomes and lower avoidable hospitalisation [41]. Finally, policies aimed at increasing job satisfaction, for example by balancing efforts and rewards, and/or by increasing the awareness of GPs about the importance of their role in health care systems, can help in this regard [42].

The results of our study demonstrate that the gatekeeper role of GPs explains only a minor part of the variance at a country level in the communications between GPs and medical specialists. Therefore, there must be characteristics of the organisation of health care at a national level that were not included in our study, but which influence the delivery of referral letters and the receipt of feedback communication by GPs. It must be also noted that, in our study, primary care practices' characteristics are not associated with receiving feedback communications from medical specialists. The receipt of these communications is more likely to depend upon medical specialists' attitudes and the characteristics of the specialist medical setting $[21,22]$.

The main strength of this study is that it involves 34 countries, and thus allows estimates to be made of the association between the organisation of primary care at a national level and the outcomes of this study. The study also allows us to assess the GPs' characteristics that are associated with communication between primary and secondary care, independent of the organisation of the primary care system in which GPs operate. Another strength is the use of multilevel regression analysis. This allows to examine simultaneously the effects of predictors at group- and at individual-levels, in order to account for the non-independence of observations within groups. It allows to examine both variation between individuals and between groups [43, 44]. With regard to the basic demographic characteristics age and gender, the study populations of GPs were representative of GPs in the respective countries [30]. Our study was conducted mainly in European countries and mostly among member states of the European Union. Three countries outside Europe participated in the study. Most of the countries participating were high income countries. This limits the generalisability of the results. We do not know whether the associations found, will also be valid in low and middle income countries and outside of Europe. The main limitation is that we have only data from GPs and, as explained above, we cannot estimate which characteristics of medical specialists involved in the referral process are associated with the delivery of referral letters and the receipt of feedback communications by GPs. Moreover, both of our outcome questions were addressed to GPs. Therefore, as we asked GPs about behaviours of medical specialists, there is a risk of reporting bias. It should also be mentioned that, in some countries, it is possible that patients self-refer to medical specialists without consulting a GP first. This may be the case particularly for certain categories of medical specialists, such as gynaecologists, internists, neurologists [32]. One of the two outcome questions included in this study ('To what extent do medical specialists inform you after they have finished the treatment or diagnostics of your patients?') might also include patients who selfreferred. Our first outcome variable was based on the 
question of whether or not GPs send referral letters. We do not have additional information on the other means of communication from GPs to specialists in the referral process. We only mentioned referral letters in the question. Therefore, there might have been communication other than through a referral letter that we have missed. This limitation does not apply to the feedback information as the means of communication were not specified. Another limitation is that the study only evaluated primary care through data collected among GPs. In some countries there are also other providers of primary care who are not included in this study [28]. A final limitation is that we only evaluated the rates of referral letters sent and feedback communications received. We do not have information about the quality of these letters and the feedback nor about the referral process as a whole [11]. The QUALICOPC study was designed to cover a broad range of topics and not as a study into referral processes. We were therefore restricted in the nature and number of questions we could use. The quality of the referral process should be further explored in international research.

\section{Conclusion}

There is a large variation among countries in the communication between GPs and medical specialists. The organisation of primary care at a country level, and specifically where there is a gatekeeping system in place, is associated with higher rates of communication. Characteristics of primary care practices and GPs are associated with rates of communication, independent of the health care system in which GPs operate. Moreover, this paper underlines the need for future studies to have a more comprehensive picture of the factors which, potentially, have a mutual relationship with the sharing of information between GPs and medical specialists in referrals.

\section{Abbreviations}

FYR Macedonia: Former Yugoslav Republic of Macedonia; GP(s): General practitioner(s); HITs: Health information technologies; ICC: Intraclass correlation; PHAMEU: Primary Health Care Activity Monitor;

QUALICOPC: Quality and Costs of Primary Care in Europe

\section{Acknowledgements}

The authors thank their partners in the QUALICOPC project for their role throughout the study and their coordination of the data collection: D Kringos (the Netherlands, NIVEL, coordinator); J De Maeseneer, E De Ryck, L Hanssens, A Van Pottelberge, S Willems (Belgium); S Greß, S Heinemann (Germany); G Capitani, S De Rosis, AM Murante, S Nuti, C Seghieri, M Vainieri (Italy); D Rotar Pavlič, I Švab (Slovenia); M Van den Berg, T Van Loenen (the Netherlands).

Authors would like to thank the coordinators of the data collection in each country: L Jorm, I McRae (Australia); K Hoffmann, M Maier (Austria); P Salchev (Bulgaria); W Wodchis, W Hogg (Canada); G Samoutis (Cyprus); B Seifert, N Šrámková (Czech Republic); J Reinholdt Jensen, P Vedsted (Den-mark); M Lember, K Pölluste (Estonia); E Kosunen (Finland); K Stavric (FYR Macedonia); C Lionis (Greece), I Rurik (Hungary); J Heimisdóttir, O Thorgeirsson (Iceland); C Collins (Ireland); G Ticmane (Latvia); S Macinskas (Lithuania), M Aubart, J Leners, R Stein (Luxembourg); G Bezzina, P Sciortino (Malta); T Ashton, R McNeill (New Zealand); T Bjerve Eide, H Melbye (Norway); M Oleszczyk, A
Windak (Poland); L Pisco (Portugal), D Farcasanu (Romania); T Dedeu (Spain); E Jurgova (Slovakia); C Björkelund, T Faresjö (Sweden); T Bisschoff, N Senn (Switzerland); M Akman (Turkey); C Sirdifield, N Siriwardena (England). Finally, authors would like to thank everyone who has supported the national coordinators in the data collection in their countries.

\section{Authors' contributions}

GS designed this analysis, performed the statistical analysis, interpreted the results and drafted the manuscript. WS designed and conducted the QUALICOPC study, advised on this analysis and its interpretation and reviewed the manuscript. WB designed and conducted the QUALICOPC study, advised on this analysis and its interpretation and reviewed the manuscript. PS advised on the analysis and performed the statistical analysis. FS advised on this analysis and its interpretation and reviewed the manuscript. PG advised on this analysis and its interpretation and reviewed the manuscript. All authors read and approved the final manuscript.

\section{Funding}

This article is based on data from the QUALICOPC (Quality and Costs of Primary Care in Europe) project, co- funded by the European Commission under the Seventh Framework Programme (FP7/2007-2013) under grant agreement 242141. The analysis, reported in this article, was not separately funded. The responsibility for the information and the views set out in this paper lie entirely with the authors.

\section{Availability of data and materials}

The datasets used and/or analysed during the current study are available from the corresponding author on reasonable request.

Ethics approval and consent to participate

Ethical approval for the QUALICOPC study was acquired in accordance with the legal requirements in each country [45]. The approving ethics committees are listed in Table 1 of the cited publication. The consenting procedure for the GPs to participate in the study is also detailed in this publication.

\section{Consent for publication}

Not applicable.

\section{Competing interests}

The authors declare that they have no competing interests.

\section{Author details}

1Department of Public Health Sciences, University of Turin, Piazza Polonia, 94, 10126 Torino, Italy. ${ }^{2}$ Department of Surgery, Northwestern University, Feinberg School of Medicine, 633 N. St Clair Street, Chicago, IL 60611, USA. ${ }^{3}$ NIVEL (Netherlands Institute for Health Services Research), PO box 1568, Utrecht 3500BN, The Netherlands. ${ }^{4}$ Department of General Practice and Elderly Care Medicine, Amsterdam Public Health Research Institute, VU University Medical Center, Van der Boechorststraat 7, Amsterdam 1081 BT, the Netherlands. ${ }^{5}$ Department of Sociology and Department of Human Geography, Utrecht University, P.O. Box 80.115, Utrecht 3508 TC, The Netherlands.

Received: 26 August 2019 Accepted: 9 March 2020

Published online: 17 March 2020

\section{References}

1. World Health Organization. The World Health Report 2008. Primary health care. Now More Than Ever. Geneva: WHO; 2008.

2. Kringos DS, Boerma WG, Hutchinson A, et al. The breadth of primary care: a systematic literature review of its core dimensions. BMC Health Serv Res. 2010;10:65.

3. Uijen AA, Schers HJ, Schellevis FG, et al. How unique is continuity of care? A review of continuity and related concepts. Fam Pract. 2012;29:264-71.

4. Haggerty JL, Reid RJ, Freeman GK, et al. Continuity of care: a multidisciplinary review. BMJ. 2003;327:1219-21.

5. Sinnige J, Korevaar JC, Westert GP, et al. Multimorbidity patterns in a primary care population aged 55 years and over. Fam Pract. 2015;32:505-13.

6. Wagner EH, Sandhu N, Coleman K, et al. Improving care coordination in primary care. Med Care. 2014;52(11 Suppl 4):S33-8. 
7. Uijen AA, Heinst CW, Schellevis FG, et al. Measurement properties of questionnaires measuring continuity of care: a systematic review. PLoS One. 2012;7:e42256

8. Haggerty $\mathrm{L}$, Pineault $\mathrm{R}$, Beaulieu MD, et al. Practice features associated with patient-reported accessibility, continuity, and coordination of primary health care. Ann Fam Med. 2008;6:116-23.

9. Shang L, Waibel S, Thomson S. Measuring care coordination: health system and patient perspectives. Report prepared for the Main Association of Austrian Social Security Institutions. London: LSE Health; 2013.

10. Epstein RM. Communication between primary care physicians and consultants. Arch Fam Med. 1995;4:403-9.

11. Forrest $C B$, Glade $G B$, Baker $A E$, et al. Coordination of specialty referrals and physician satisfaction with referral care. Arch Pediatr Adolesc Med. 2000;154: 499-506.

12. Schoen C, Osborn R, Huynh PT, et al. On the front lines of care: primary care doctors' office systems, experiences, and views in seven countries. Health Aff. 2006:25:w555-71.

13. Anderson R, Barbara A, Feldman S. What patients want: a content analysis of key qualities that influence patient satisfaction. J Med Pract Manage. 2007;22:255-61.

14. Gandhi TK, Sittig DF, Franklin M, et al. Communication breakdown in the outpatient referral process. J Gen Intern Med. 2000;15:626-31.

15. O'Malley AS, Cunningham PJ. Patient experiences with coordination of care: the benefit of continuity and primary care physician as referral source. J Gen Intern Med. 2009;24:170-7.

16. Garasen $H$, Johnsen R. The quality of communication about older patients between hospital physicians and general practitioners: a panel study assessment. BMC Health Serv Res. 2007;7:133.

17. Sutcliffe KM, Lewton E, Rosenthal MM. Communication failures: an insidious contributor to medical mishaps. Acad Med. 2004;79:186-94.

18. Foot CNC, Imison C. The quality of GP diagnosis and referral. London: King's Fund; 2010.

19. Coulter A. Does the referral system work? In: Roland M, Coulter A, editors. Hospital referrals. Oxford: Oxford University Press; 1992.

20. Vermeir $P$, Vandijck D, Degroote $S$, et al. Communication in healthcare: a narrative review of the literature and practical recommendations. Int J Clin Pract. 2015;69:1257-67.

21. Stille CJ, McLaughlin TJ, Primack WA, et al. Determinants and impact of generalist-specialist communication about pediatric outpatient referrals. Pediatrics. 2006:118:1341-9.

22. O'Malley AS, Reschovsky JD. Referral and consultation communication between primary care and specialist physicians: finding common ground. Arch Intern Med. 2011;171:56-65.

23. Gandhi TK, Keating NL, Ditmore M, et al. Improving referral communication using a referral tool within an electronic medical record. In: Henriksen K Battles JB, Keyes MA, et al., editors. Advances in patient safety: new directions and alternative approaches (Vol 3: performance and tools). Rockville: Agency for Healthcare Research and Quality; 2008.

24. Hsiao CJ, King J, Hing E, et al. The role of health information technology in care coordination in the United States. Med Care. 2015;53(2):184-90.

25. Crombie DL, van der Zee J, Backer P. The interface study. COMAC-HSR in collaboration with European General Practice Research Workshop. Occasional Paper 48. 1990. London Royal College of general Practictioners, England.

26. Boerma WG, van der Zee J, Fleming DM. Service profiles of general practitioners in Europe. European GP task profile study. Br J Gen Pract. 1997; 47:481-6.

27. Boerma W. Corrdination and integration in European primary care. In Saltman R, Rico, a, Boerma, W. primary care in the driver's seat? Organizational reform in European primary care. Maidenhead: Open University Press; 2006.

28. Schafer WL, Boerma WG, Kringos DS, et al. QUALICOPC, a multi-country study evaluating quality, costs and equity in primary care. BMC Fam Pract. 2011;12:115

29. Schafer WL, Boerma WG, Kringos DS, et al. Measures of quality, costs and equity in primary health care instruments developed to analyse and compare primary care in 35 countries. Qual Prim Care. 2013;21:67-79.

30. Groenewegen PP, Greß S, Schäfer W. General practitioners' participation in a large, multi-country combined general practitioner - patient survey: recruitment procedures and participation rate. Int J Family Med. 2016: 4929432. https://doi.org/10.1155/2016/4929432.
31. Kringos DS, Boerma WG, Bourgueil $Y$, et al. The European primary care monitor: structure, process and outcome indicators. BMC Fam Pract. 2010; $11: 81$

32. Kringos DS, Boerma WG, Hutchinson A, et al. Building primary care in a changing Europe. WHO regional Office for Europe. Copenhagen: The European Observatory on Health Systems and Policies; 2015.

33. Schafer WL, Boerma WG, Murante AM, et al. Assessing the potential for improvement of primary care in 34 countries: a cross-sectional survey. Bull World Health Organ. 2015;93:161-8.

34. Groenewegen PP, Hutten JB. Workload and job satisfaction among general practitioners: a review of the literature. Soc Sci Med. 1991:32:1111-9.

35. Groenewegen $P$, Heinemann $S$, Gress $S$, et al. Primary care practice composition in 34 countries. Health Policy. 2015;119:1576-83.

36. Snijders TAB, Bosker RJ. Multilevel analysis: an introduction to basic and advanced multilevel modeling. 2nd ed. London: Sage Publishers; 2012.

37. Scheepers RA, Boerebach BC, Arah OA, et al. A systematic review of the impact of Physicians' occupational well-being on the quality of patient care. Int J Behav Med. 2015;22:683-98.

38. Gottschalk A, Flocke SA. Time spent in face-to-face patient care and work outside the examination room. Ann Fam Med. 2005:3:488-93.

39. Ferre F, de Belvis AG, Valerio L, et al. Italy: health system review. Health systems in transition. 2014;16:1-168.

40. Milieu Ltd, Time.lex. Overview of the nationals laws on electronic health records in EU Member States and their interaction with the provision of cross-boarder health services. Bruxelles; 2014. Available at http://ec.europa. eu/health/ehealth/docs/laws_report_recommendations en.pdf. Accessed 16 Feb 2016

41. Martinez-Gonzalez NA, Berchtold P, Ullman K, et al. Integrated care programmes for adults with chronic conditions: a meta-review. Int J Qual Health Care. 2014;26:561-70

42. Siegrist J, Shackelton $\mathrm{R}$, Link $\mathrm{C}$, et al. Work stress of primary care physicians in the US, UK and German health care systems. Soc Sci Med. 2010;71:298-304.

43. Diez-Roux AV. Multilevel analysis in public health research. Annu Rev Public Health. 2000;21:171-92.

44. Leyland AH, Groenewegen PP. Multilevel modelling for public health and health services research: health in context. Springer Open, 2020.

45. De Rosis S, Seghieri C. Basic ICT adoption and use by general practitioners: an analysis of primary care systems in 31 European countries. BMC Med Inform Decis Mak. 2015:15:70.

\section{Publisher's Note}

Springer Nature remains neutral with regard to jurisdictional claims in published maps and institutional affiliations.

Ready to submit your research? Choose BMC and benefit from:

- fast, convenient online submission

- thorough peer review by experienced researchers in your field

- rapid publication on acceptance

- support for research data, including large and complex data types

- gold Open Access which fosters wider collaboration and increased citations

- maximum visibility for your research: over $100 \mathrm{M}$ website views per year

At BMC, research is always in progress.

Learn more biomedcentral.com/submissions 